\title{
Nutritional and Social Correlates of Gestational Diabetes
}

\author{
A. Brennan ${ }^{1}$, L. Mullaney ${ }^{1}$, E. Fox ${ }^{1}$, S. Cawley ${ }^{1}$, N. Daly ${ }^{2}$, M. Farren ${ }^{2}$, D. McCartney ${ }^{1}$ and \\ M.J. Turner ${ }^{2}$ \\ ${ }^{1}$ School of Biological Sciences, Dublin Institute of Technology, Dublin and ${ }^{2} U C D$ Centre for Human Reproduction, \\ CWIUH, Dublin
}

Gestational diabetes mellitus (GDM) is associated with adverse outcomes for the mother; and also for the fetus, neonate, child and adult offspring of the affected pregnancies. The aim of this study was to investigate maternal energy and macronutrient intakes in the first trimester of pregnancy in relation to the development of gestational diabetes.

Women were recruited after sonographic confirmation of a singleton pregnancy in the first trimester. Dietary information was collected using the validated Willett Food Frequency Questionnaire. Lowest plausible thresholds for physical activity levels (PAL) were calculated according to respondents' individual reported PAL ${ }^{(1)}$. Those whose ratio of energy intake (EI) to their calculated basal metabolic rate (BMR) (EI/BMR) fell below the calculated plausible threshold for their physical activity category were classified as dietary under-reporters ${ }^{(2)}$. Under-reporters were excluded from nutrient analyses to enhance the integrity of the data ${ }^{(3)}$. Women who had existing diabetes were also excluded. Maternal height and weight were measured and BMI calculated. GDM was diagnosed using a $75 \mathrm{~g} 2$ hour glucose tolerance test between 24 and 28 weeks gestation.

The mean age of the sample $(n=516)$ was $30.03 \pm 5.3$ years. The mean weight was $69.2 \pm 14.59 \mathrm{~kg}$ and mean BMI was $25.36 \pm 5.52$ $\mathrm{kg} / \mathrm{m}^{2}$, with $16 \cdot 3 \%$ obese. Of the total sample, 25 women $(4.8 \%)$ developed GDM. Characteristics of the women who developed GDM compared to non-GDM women are shown in table 1. A higher proportion of women with GDM were under-reporters compared to women without GDM $(P=0.03)$. There was no difference in EI ( $2326.5 \mathrm{vs} 2299.5 \mathrm{kcal})$, or \% energy from protein $(18.57 \mathrm{vs}$ $18.72)$, fat (36.33 vs 36.75$)$ or carbohydrate (46.36 vs 47.02$)$ between women with GDM and those without GDM. In relation to social factors, women experiencing relative income poverty were particularly likely to develop GDM.

Table 1. Characteristics of GDM vs non-GDM women

\begin{tabular}{|c|c|c|c|}
\hline & GDM $(n=25)$ & Non-GDM $(n=491)$ & P-value \\
\hline Weight $(\mathrm{kg})^{1}$ & $84.95(19.44)$ & $68.45(13 \cdot 85)$ & $<0.001$ \\
\hline $\operatorname{BMI}\left(\mathrm{kg} / \mathrm{m}^{2}\right)^{1}$ & $30 \cdot 69(5 \cdot 82)$ & $25.08(5 \cdot 37)$ & $<0.001$ \\
\hline Consistent Poverty $^{2, \mathrm{a}}$ & $5(20)$ & $52(11 \cdot 1)$ & NS \\
\hline Relative Deprivation $^{2}$ & $6(24)$ & $166(33 \cdot 8)$ & NS \\
\hline Relative Income Poverty ${ }^{2, a}$ & $11(44)$ & $108(23)$ & $0 \cdot 031$ \\
\hline Energy Underreporters ${ }^{2}$ & $11(44)$ & $111(22 \cdot 6)$ & $0 \cdot 027$ \\
\hline
\end{tabular}

${ }^{1}$ mean (standard deviation) ${ }^{2}$ number (percentage) ${ }^{\text {a }}$ data on $n=500$

The high proportion of energy under-reporters who developed GDM in this study, as well as the biases introduced by the exclusion of these dietary under-reporters, may generate misleading associations between dietary and nutrient intakes and obstetric outcome. These excluded energy under-reporters appear to be at increased risk of GDM and may therefore benefit from nutritional intervention.

1. Black AE (2000) Int J Obes Relat Metab Disord 24, 1119-1130.

2. Goldberg GR, Black AE, Jebb SA, Cole TJ, Murgatroyd PR, Coward WA et al. (1991) Eur J Clin Nutr 45, $569-581$.

3. Livingstone MB, Black AE. (2003) J Nutr. 133 (3), 895S-920S. 